\title{
Characterization of Acidic Compounds in Brazilian Tar Sand Bitumens by LTQ Orbitrap XL: Assessing Biodegradation Using Petroleomics
}

\author{
Laercio L. Martins, ${ }^{a}$ Célio Fernando F. Angolini, ${ }^{b}$ Georgiana F. da Cruz ${ }^{*, a}$ and \\ Anita J. Marsaioli ${ }^{b}$
}

\author{
${ }^{a}$ Laboratório de Engenharia e Exploração de Petróleo (LENEP), \\ Universidade Estadual do Norte Fluminense Darcy Ribeiro (UENF), \\ 27910-970 Macaé-RJ, Brazil \\ ${ }^{b}$ Instituto de Química, Universidade Estadual de Campinas (UNICAMP), \\ 13084-971 Campinas-SP, Brazil
}

\begin{abstract}
A set of eight tar sand samples with identical source, from sedimentary facies of the Pirambóia Formation, Paraná Basin, provides an interesting opportunity to assess the biodegradation extent of bitumens using high-resolution mass spectrometry with Orbitrap mass analyzer. The results suggest that acidic compounds have been degraded by microorganisms, since the $\mathrm{O}_{2}$ and $\mathrm{O}_{3}$ classes were lower to bitumens from dry interdune facies, the most biodegraded. It was also proposed a new parameter to evaluate biodegradation, DBE ratio (ratio between acidic species with the same number of double bond equivalent), that was used together with the already proposed A/C ratio (acyclic to cyclic naphthenic acids), both obtained from $\mathrm{O}_{2}$ class distribution. The bitumens from dry interdune facies presented the highest DBE ratios and lowest $\mathrm{A} / \mathrm{C}$ ratios, which suggested that these parameters can be used to assess the extent of bitumen biodegradation in which the DBE ratios increase and the $\mathrm{A} / \mathrm{C}$ ratios decrease with increasing biodegradation.
\end{abstract}

Keywords: heavy oil, biodegradation, heteroatom class, sedimentary facies, Paraná Basin

\section{Introduction}

It is expected that the production of heavy, biodegraded oil will increase worldwide as lighter conventional oil reserves are depleted. ${ }^{1}$ This shortage of light oil makes these less attended energy resources more attractive, especially considering that heavy oils are currently 10 times more abundant than conventional oils. ${ }^{2}$ Even with the fluctuation of crude oil prices, unconventional oil probably will gain a considerable market share in the short term, although conventional oil remains as a major source of global oil market in the long term. ${ }^{3}$ Therefore, these unconventional oils are potential resources that could be used to fulfill current and future energy requirements. Among these unconventional oils, bitumens from tar sand reservoirs have great potential to assist in meeting the world's rising energy demand. ${ }^{4,5}$

The occurrence of tar sand bitumens is common in many basins worldwide, but they are mainly found in shallow reservoirs on the flanks of foreland basins in North

*e-mail: geofec@gmail.com and South America. The largest accumulations are the supergiant deposits of tar sands in the Alberta (Canada) and Eastern Venezuelan (Venezuela) basins. ${ }^{67}$ In Brazil, there are tar sand bitumen accumulations in the Paraná Basin, mostly occurring in sandstones of the Triassic Pirambóia Formation. These tar sands are restricted to the eastern margin, with approximately 25 known localities spread over two areas in the state of São Paulo. The Anhembi Exudation area is one of the major heavy oil exudations in this area. The oil reservoir was estimated at 5,712,000 barrels based on a mean content of $5.5 \%$ weight oil. These bitumen deposits have a high viscosity and medium-to-high sulfur content (2-3\% by weight). ${ }^{8}$

The Paraná Basin is a very large intracratonic basin in which the tar sand accumulations are attributed to the Irati-Pirambóia petroleum system. ${ }^{8,9}$ In the Pirambóia Formation, there are four different sedimentary eolic facies, with different physicochemical characteristics: dune foreset, which has better permo-porosity; dune bottomset, which has an intermediate permo-porosity; and wet and dry interdune, which have the worst permo-porosity. The dune foreset and dune bottomset facies were formed in high 
energy processes by deposition of the dunes. In contrast, the interdune facies were formed by lower energy processes, with the groundwater elevation level, showing a semihorizontal stratification. ${ }^{10,11}$

Tar sand reservoirs are commonly characterized by fluids that have highly variable physical and chemical properties, ${ }^{1}$ mainly due to differing extents of biodegradation and other post-accumulation alteration processes, such as water washing, in reservoir maturation, and the fractionation of light and heavy ends due to migration. ${ }^{12,13}$ Some parameters, such as viscosity, may vary by several orders of magnitude within a single penetrated reservoir section. ${ }^{1}$

The effects of biodegradation on the hydrocarbon composition and physical properties of crude oil, as well as the geological conditions, types of microorganisms, and their biochemical pathways, are well known. ${ }^{14-18}$ The oxidation of oil during biodegradation decreases the saturated hydrocarbon content and API gravity (American Petroleum Institute gravity), whereas oil density, metal, polar compound contents, and acidity increase. Thus, biodegraded oil negatively affects oil production and refining operations, reducing oil value., ${ }^{7,19,20}$

The effects of biodegradation on polar species are much less established than those on hydrocarbons. The analysis of polar compounds, in general, suffers from their thermal instability, low volatility, and ineffective separation and detection by the analytical techniques most commonly used to analyze petroleum composition, such as chromatography and mass spectrometry. ${ }^{21,22}$ Moreover, analytical systems often lack the chromatographic resolution and mass resolving power to identify individual compounds, particularly in the case of severely biodegraded oil samples containing noticeable amounts of polar components. ${ }^{23}$

Recently, some high resolution and high mass accuracy analytical techniques became commercially available, such as Fourier transform ion cyclotron resonance mass spectrometry (FT-ICR MS) and Orbitrap Fourier transform mass spectrometry (Orbitrap FT MS). These techniques are capable of analyzing several hundred thousand polar compounds in a petroleum mixture at once. ${ }^{24}$ This application is made possible by coupling the techniques to soft ionization sources, e.g., electrospray ionization (ESI) and atmospheric pressure photoionization (APPI). ${ }^{25,26}$ Thus, these systems allow the efficient ionization of complex samples and provide sufficient resolving power, mass accuracy, and spectral dynamic range to differentiate between thousands of ions and unambiguously identify their elemental compositions. ${ }^{27,28}$

Both of the high-resolution mass spectrometers discussed above have emerged as invaluable tools in analyzing the chemical composition of petroleum. ${ }^{29,30}$
Because each molecule has a distinct elemental composition, e.g., $\mathrm{C}_{\mathrm{c}} \mathrm{H}_{\mathrm{h}} \mathrm{N}_{\mathrm{n}} \mathrm{O}_{\mathrm{o}} \mathrm{S}_{\mathrm{s}}$, has a unique exact mass, sufficiently high mass-resolving power and mass accuracy make it possible to simultaneously resolve and identify each of the thousands of compounds found in petroleum. Additionally, it is possible to separate and classify petroleum components according to their heteroatom class $\left(\mathrm{N}_{\mathrm{n}} \mathrm{O}_{\mathrm{o}} \mathrm{S}_{\mathrm{s}}\right)$, double bond equivalent (DBE), and carbon number. This characterization of petroleum at the molecular level is called "petroleomics". 31

Petroleomics has been previously used to analyze the composition of acidic compounds and the degree of petroleum biodegradation, including heavy-oil and tar sand reservoirs..$^{22,30,32-36}$ These studies involved mainly the $\mathrm{O}_{2}$ species distribution, and some biodegradation indexes have been suggested. Kim et al. ${ }^{32}$ suggested that $\mathrm{A} / \mathrm{C}$ ratio (acyclic to cyclic naphthenic acids) could be used as a measure of the degree of biodegradation, based on the consistent decrease in acyclic fatty acids and increase in cyclic $\mathrm{O}_{2}$ species with microbial degradation. Other biodegradation indexes suggested by Vaz et $a l .{ }^{33}$ are a modification on $\mathrm{A} / \mathrm{C}$ ratio, which was made to take 4- and 5-ring naphthenic acids into account, calculating the ratio between DBE 1 and DBE 2-6, and saturated acid (SA) index calculated by the sum of relative abundance of DBE 1-6 for the class $\mathrm{O}_{2}$, in which a plot using both modified $\mathrm{A} / \mathrm{C}$ and SA indexes was useful to assess biodegradation extent. Angolini et al.$^{30}$ proposed a biodegradation scale using $\mathrm{O}_{2}$ compounds, based on the fact that compounds with less complex structures (lower DBE) are more depleted than those with more complex structures (higher DBE).

In this work, the acidic fractions of tar sand bitumens from eolic sedimentary facies of the Pirambóia Formation (Paraná Basin, Brazil) were analyzed by negative-ion ESI LTQ Orbitrap XL to characterize acidic compounds by their heteroatom classes. The LTQ Orbitrap XL presents lower costs relative to typical FT ICR instruments, but it still retains sufficient resolution to assign molecular formulas to individual components present in mixtures, mainly those of relatively high abundance. ${ }^{29,30}$ In this context, the influence of biodegradation on the acidic species composition was explored by $\mathrm{O}_{2}$ species distribution, DBEs, and $\mathrm{A} / \mathrm{C}$ ratios.

\section{Experimental}

\section{Samples and pretreatment}

The rock sample suite comprises outcrop tar sands of the Pirambóia Formation (filled with identical source bitumens), from the eastern margin of Paraná Basin, which were collected during geological fieldwork and cataloged 
according to their eolic sedimentary facies. ${ }^{11}$ The samples were from four different localities in the state of São Paulo, Brazil: Mina Farm; Betumita Farm; Bofete Farm; and Guareí. ${ }^{37,38}$ Eight samples were selected, two of each sedimentary facies: dry interdune (S12 and S14, from Mina Farm); dune foreset (S26 and S28, from Betumita Farm); wet interdune ( $\mathrm{S} 03$ and $\mathrm{S} 04$, from Bofete Farm); and dune bottomset (S27 and S33, from Betumita Farm).

The rock samples were all crushed and pulverized before bitumen extraction with dichloromethane (chromatographic grade from Sigma-Aldrich) using a Soxhlet system for 72 hours. For analysis by negative-ion ESI LTQ Orbitrap XL, the acid fraction was obtained by $\mathrm{KOH}$ modified silica gel column chromatography. The bitumens were first eluted with ether to obtain the neutral fraction and then eluted with ether:formic acid $(20 \%)$ to obtain the acidic fraction. ${ }^{39}$ The ether:formic acid mixture was evaporated under vacuum. These acidic fractions were typically dissolved at concentrations of $0.5 \mathrm{mg} \mathrm{mL}^{-1}$ in toluene:methanol $(1: 1 \mathrm{v} / \mathrm{v})$ with $0.5 \%$ of $\mathrm{NH}_{4} \mathrm{OH}$. The solvents are HPLC grade from Merck or JTbaker.

\section{LTQ Orbitrap XL analysis}

A ThermoFisher Scientific LTQ Orbitrap XL mass spectrometer, equipped with an external ESI source was used in the negative ion mode to analyze the acidic fraction. A spray voltage of $3.6 \mathrm{kV}$ was applied to the tip. The capillary voltage and capillary temperature were kept constant at $48 \mathrm{~V}$ and $275^{\circ} \mathrm{C}$, respectively. Mass spectra were acquired in a mass range of $\mathrm{m} / z$ 200-1000. A resolution of 100000 at $\mathrm{m} / \mathrm{z} 400$ was used in all experiments. A syringe pump was used for direct infusion.

Data acquisition and processing were performed by Xcalibur, which attributed the molecular formula with elemental composition restricted to $\mathrm{C}_{100}{ }^{13} \mathrm{C}_{2} \mathrm{H}_{200} \mathrm{O}_{4} \mathrm{~N}_{2}$, accepting only formulas with errors below $3 \mathrm{ppm}$. Post-acquisition mass spectra recalibration procedure was applied, using RecalOffline, a tool from Xcalibur software. Microsoft Excel 2007 was used to data reorganization and to build the distribution of heteroatom classes. Origin ${ }^{\circledR} 8$ was used to do the iso-abundance plots of DBE versus carbon number for $\mathrm{O}_{2}$ class species.

\section{Results and Discussion}

The bitumen samples used in this work were already analyzed by gas chromatography with flame ionization detector (GC-FID) to assess the extent of biodegradation. ${ }^{37,38}$ The chromatograms obtained by GC-FID analysis (usually called fingerprints) are given in Figure 1.
Martins et al. ${ }^{37}$ showed that the chromatograms obtained for all bitumen samples (Figure 1) reveal absence of $n$-alkanes and the isoprenoids pristane (Pr) and phytane $(\mathrm{Ph})$. This result suggests a heavy level of biodegradation in Peters and Moldowan (PM) biodegradation scale (more than 5 PM).$^{40}$ However, it was observed a lower abundance of hydrocarbons to the bitumens from dry interdune facies, mainly to sample S12. Furthermore, the bitumens from this facies show a higher content of asphaltenes (\% Asph) and lower content of saturated hydrocarbons (\%Sat) than bitumens from the other facies, which suggested highest biodegradation extent for the dry interdune facies (S12 and S14). ${ }^{11}$

In this work, we present another technique to assess biodegradation in bitumens, evaluating the acidic composition by ESI LTQ Orbitrap XL. Pomerantz et al. ${ }^{29}$ have already used this alternative technique to analyze whole oil, proposing the Orbitrap as method for routine analysis of the composition of the more abundant compounds in the polar fraction of petroleum. However, the analysis of acidic fraction instead the whole oil improves the MS analysis by avoiding unresolved compounds due to limited resolution of standard Orbitrap. Angolini et al. ${ }^{30}$ have already used this technique in the same way to evaluate biodegradation of a set of oil with different levels of biodegradation (slight to severe levels), and they proposed a new biodegradation scale using $\mathrm{O}_{2}$ compounds. Besides, Kim et al. ${ }^{32}$ and Hughey et al..$^{34}$ have previously presented FT-ICR MS results showing how biodegradation can affect the composition of polar compounds. Smith et al..$^{35}$ used the same high-resolution mass accuracy technique to characterize the acidic species in Canadian bitumen (Athabasca oil sands), and Liao et al..$^{22}$ used this technique to analyze bitumens from the Liaohe Basin of Northeast China, studying the change in oil composition or compound class distribution based on the degree of biodegradation severity.

Figure 2 shows the broadband negative ion LTQ Orbitrap XL mass spectra of the acidic fractions separated from tar sand bitumens of sedimentary facies of the Pirambóia Formation. The number of components and the average molecular weight of the polar compounds are distinct to bitumens from the dry interdune facies in comparison with the other facies. These most biodegraded bitumens contain the largest number of peaks, as can be clearly observed in Figure 2. The S12 and S14 bitumen samples analyzed in this work have a Peters and Moldowan (PM $)^{40}$ level greater than 5 , and the number of heteroatom compounds begins to increase with this high level of biodegradation likely due to the formation of new polar compounds through the biodegradation of the previously formed polar compounds. These compounds are not bioresistant, and can suffer 
(a) Dry interdune

$\mathrm{S} 12$

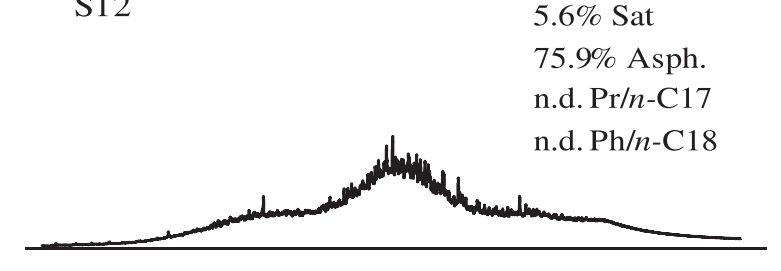

(b) Dune foreset

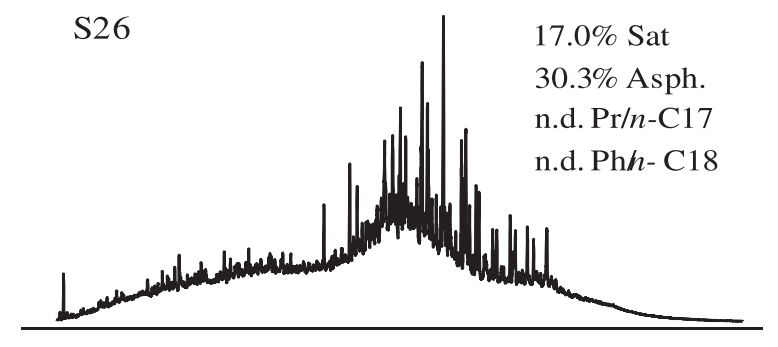

(c) Wet interdune

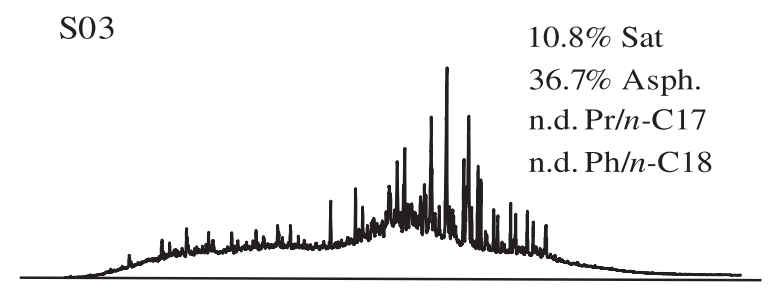

(d) Dune bottomset

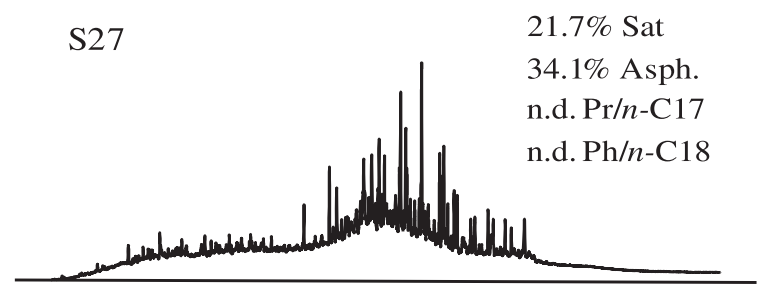

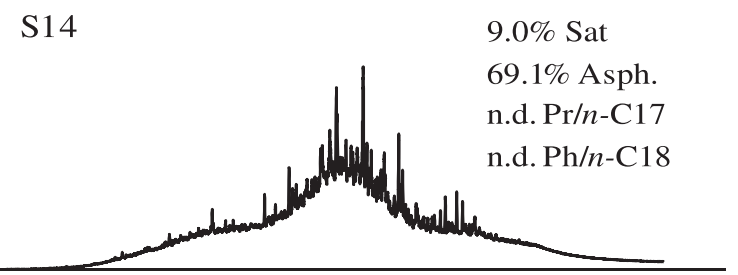

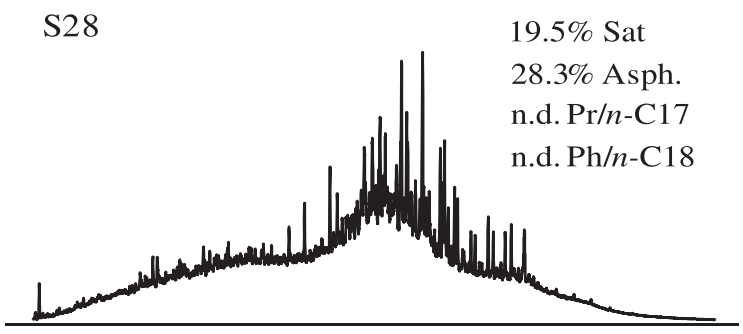

S04

$11.8 \%$ Sat

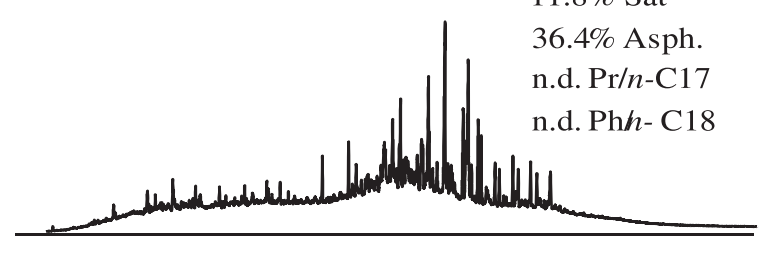

$12.7 \%$ Sat

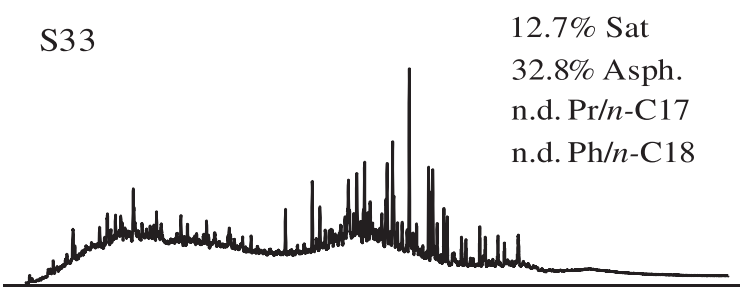

Figure 1. Chromatograms obtained by GC-FID of saturated hydrocarbons in bitumen samples from (a) dry interdune facies (S12 and S14); (b) dune foreset (S26 and S28); (c) wet interdune (S03 and S04); (d) dune bottomset facies (S27 and S33) of Pirambóia Formation, Paraná Basin, Brazil. ${ }^{37}$

selective degradation process as complex as those that affect hydrocarbons. ${ }^{32,41}$ For instance, acyclic acids, which can be products from the biodegradation of acyclic hydrocarbons, ${ }^{30}$ have greatest susceptibility among $\mathrm{O}_{2}$ species to microbial degradation, as showed by Kim et al. ${ }^{32}$

Figure 3 shows the expanded view from $m / z 453$ to 455 , showing attributed classes with errors below $3 \mathrm{ppm}$. In fact, the analysis of acidic fraction instead of crude oil improved the MS analyses by avoiding unresolved compounds due to limited resolution of Orbitrap (100 000 at $\mathrm{m} / \mathrm{z} 400){ }^{30}$

\section{Compound class distribution}

The relative abundances of compound classes in the acidic fractions can be found in Figure 4. The compound classes identified are characterized by the type and the number of heteroatoms. $\mathrm{N}_{1}, \mathrm{~N}_{2}, \mathrm{~N}_{1} \mathrm{O}_{1}, \mathrm{~N}_{1} \mathrm{O}_{2}, \mathrm{~N}_{1} \mathrm{O}_{3}, \mathrm{~N}_{1} \mathrm{O}_{4}, \mathrm{~N}_{2} \mathrm{O}_{1}, \mathrm{~N}_{2} \mathrm{O}_{2}$, $\mathrm{N}_{2} \mathrm{O}_{3}, \mathrm{~N}_{2} \mathrm{O}_{4}, \mathrm{O}_{1}, \mathrm{O}_{2}, \mathrm{O}_{3}$, and $\mathrm{O}_{4}$ classes were found to be present in the acidic fractions. Relative abundance of each class was calculated by normalizing the peak abundance to the total abundance (all the assigned peaks). In the presented compound class distribution of bitumen acidic fractions, the greatest relative abundances were observed for $\mathrm{O}_{2}, \mathrm{O}_{3}$, and $\mathrm{O}_{4}$ classes that mainly represent carboxylic acids (e.g., $\mathrm{O}_{2}$ and $\mathrm{O}_{4}$ species are, presumably, carboxylic and dicarboxylic acids, respectively), and the least relative abundances were observed for the other classes, which represent acidic nitrogen compounds.

Among the $\mathrm{O}_{0}$ classes (Figure 4), the $\mathrm{O}_{1}$ class showed the lowest abundance. This class is dominated by alcohols 

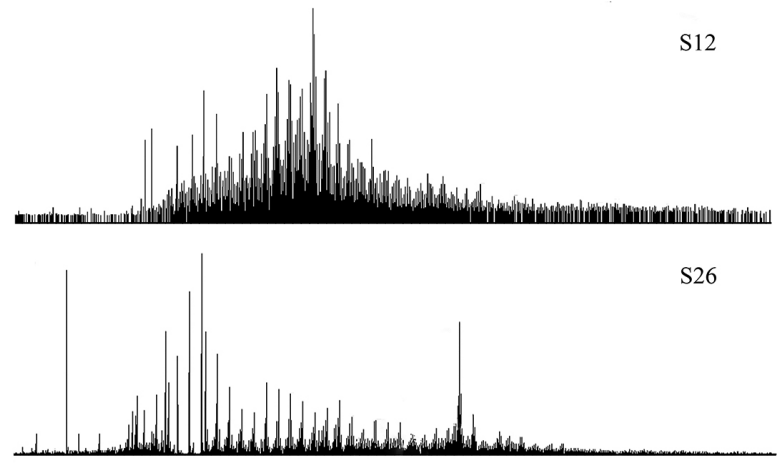

$\mathrm{S} 03$
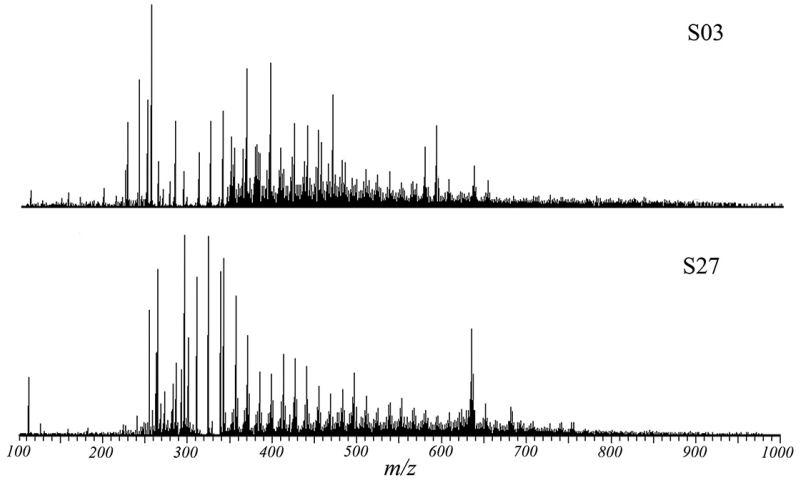

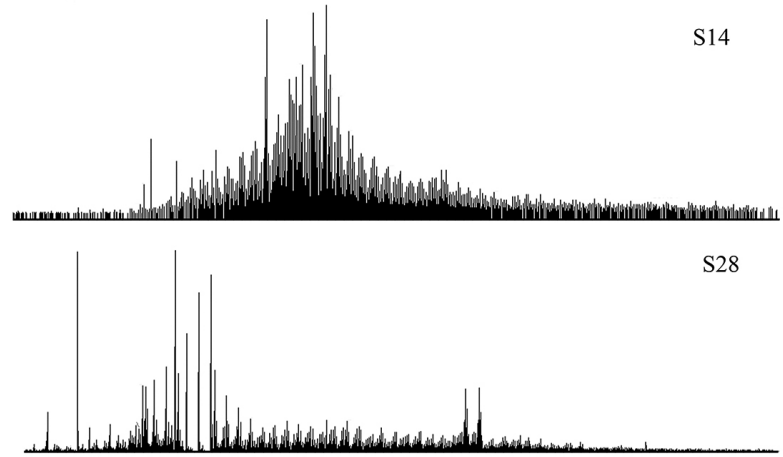

$\mathrm{S} 04$

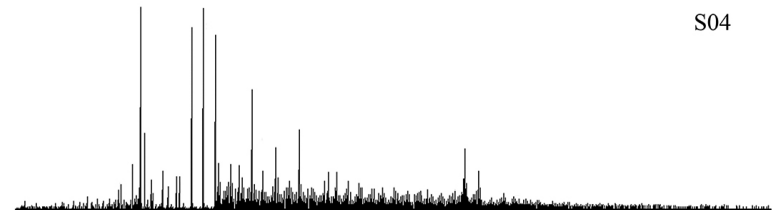

S33

Figure 2. Negative-ion ESI LTQ Orbitrap XL mass spectra of the acidic fractions separated from tar sand bitumen samples from the Pirambóia Formation: S12 and S14 from dry interdune facies; S26 and S28 from dune foreset facies; S03 and S04 from wet interdune facies; S27 and S33 from dune bottomset facies.

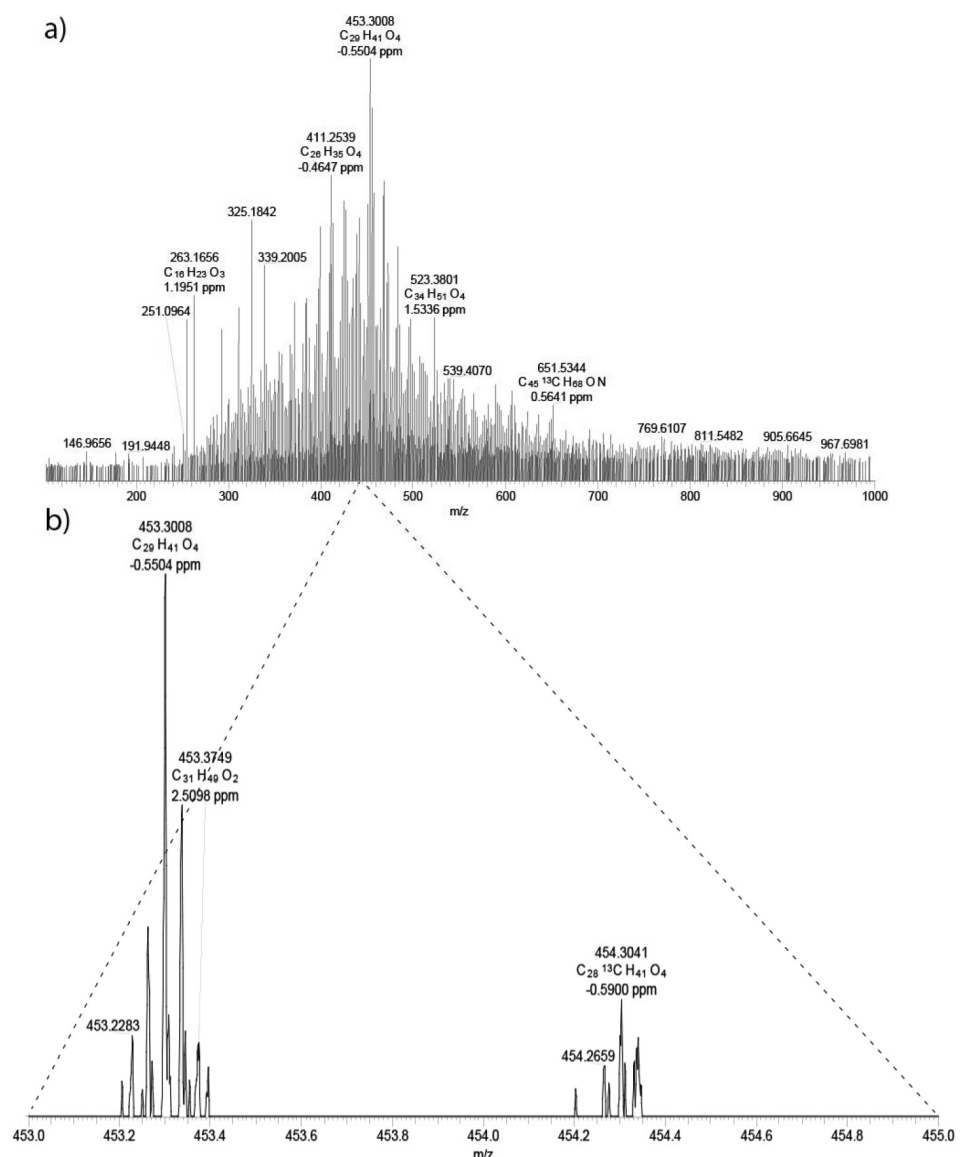

Figure 3. (a) Sample 12 negative-ion ESI LTQ Orbitrap XL mass spectrum; (b) their expanded view from $\mathrm{m} / \mathrm{z} 453$ to 455 showing atributted classes with errors below $3 \mathrm{ppm}$. 


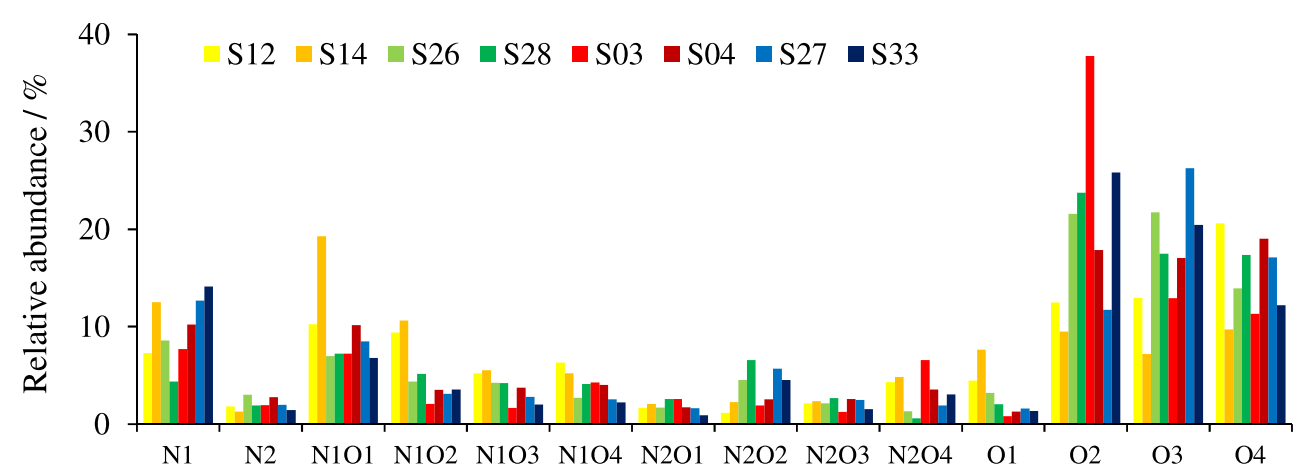

Figure 4. Distribution of heteroatom classes determined by negative-ion ESI LTQ Orbitrap XL mass spectra for acidic fractions of bitumen samples: S12 and S14 from dry interdune facies; S26 and S28 from dune foreset facies; S03 and S04 from wet interdune facies; S27 and S33 from dune bottomset facies.

and other compounds that are considered intermediates in a number of petroleum component biodegradation pathways. ${ }^{22,42}$ Because these bitumen samples are severely biodegraded, these intermediates compounds may be almost completely consumed during further biodegradation under aerobic and anaerobic conditions, as was shown by Harwood et al. ${ }^{41}$

The relative abundance of $\mathrm{O}_{2}$ and $\mathrm{O}_{3}$ classes in general is lower in the acidic fraction of bitumens from the dry interdune facies (S12 and S14). These are the most biodegraded bitumens, so their low abundance is an indication that the acidic compounds have been degraded by microorganisms. The GC-MS analyses showed the absence of most hopanes in these samples (data not shown), which may indicate that with the almost complete depletion of these hydrocarbons, the degradation of the carboxylic acids, such as hopanoic acids formed by the oxidation of corresponding hopanes, becomes more intense. However, the relative abundances of the $\mathrm{N}_{1} \mathrm{O}_{1}$, $\mathrm{N}_{1} \mathrm{O}_{2}, \mathrm{~N}_{1} \mathrm{O}_{3}$, and $\mathrm{N}_{1} \mathrm{O}_{4}$ classes are higher in the most biodegraded samples. This result is in agreement with the fact that $\mathrm{N}_{1} \mathrm{O}_{2}$ compounds appear to be biodegradation products of $\mathrm{N}$-containing compounds, being formed by the ring opening of hydroxyl dibenzocarbazoles with the addition of carboxyl group. ${ }^{22}$

The distribution of $\mathrm{O}_{2}$ species

The $\mathrm{O}_{2}$ species in petroleum and bitumen are presumably carboxylic acids ("naphthenic"). Mapolelo et al. ${ }^{36}$ showed that the high relative abundance of $\mathrm{O}_{2}$ species in Angola crude oil and Athabasca bitumen suggests extensive biodegradation.

Other works have performed detailed analyses of naphthenic acids in crude oils. ${ }^{19,32}$ According to Watson et al. ${ }^{43}$ carboxylic acids in crude oil could have three possible sources: primary acids from the source rock, oil biodegradation products, and acids biosynthesized by microorganisms. The carboxylic acids in crude oil may be continuously removed by post-accumulation process, such as further biodegradation, water washing, and thermal alteration. ${ }^{41}$ In this work, we suggest that the $\mathrm{O}_{2}$ species were formed by the chemical and biochemical oxidation of crude oil after migration into the reservoir, but with further biodegradation, the $\mathrm{O}_{2}$ species began to degrade. Kim et al..$^{32}$ showed that polar components are not bioresistant, as once believed, and that these compounds undergo selective degradation processes as complex as those that affect hydrocarbons.

Figure 5 shows the abundance plots of DBE versus carbon number for the $\mathrm{O}_{2}$ class in the acidic fractions of the eight bitumen samples. It can be observed that the $\mathrm{O}_{2}$ class distribution is very similar to that of bitumens from the same sedimentary facies, but this distribution differs among the different facies. Bitumens S12 and S14 (dry interdune facies) have less fatty acids and isoprenoid acids $(\mathrm{DBE}=1)$ than the others because fatty acids have the greatest susceptibility to biodegradation among the $\mathrm{O}_{2}$ compounds. ${ }^{22,30,32}$ Furthermore, these samples have the least number of $\mathrm{O}_{2}$ species when compared to the other samples, with a narrower carbon number range and almost no species below 20 carbons. These results are in agreement with the highest level of biodegradation in bitumens from the dry interdune, resulting in the consumption of acidic compounds as reported by Angolini et al. ${ }^{30}$

The $\mathrm{O}_{2}$ species with DBE values from 2 to 7 are naphthenic acids of 1-6 rings. ${ }^{44}$ Watson et al. ${ }^{43}$ showed that hopanoic acids (species with DBE 6) could be formed by the oxidation of corresponding hopanes during aerobic biodegradation of crude oils by side chain oxidation. Species with DBE $>7$ are likely multi-ring naphthenic acids and aromatic acids. ${ }^{41}$

To better differentiate the acidic species composition among the bitumens studied in this work, and also assess the biodegradation extent, we suggested the use of DBE ratios, which can be called petroleomics parameters. 

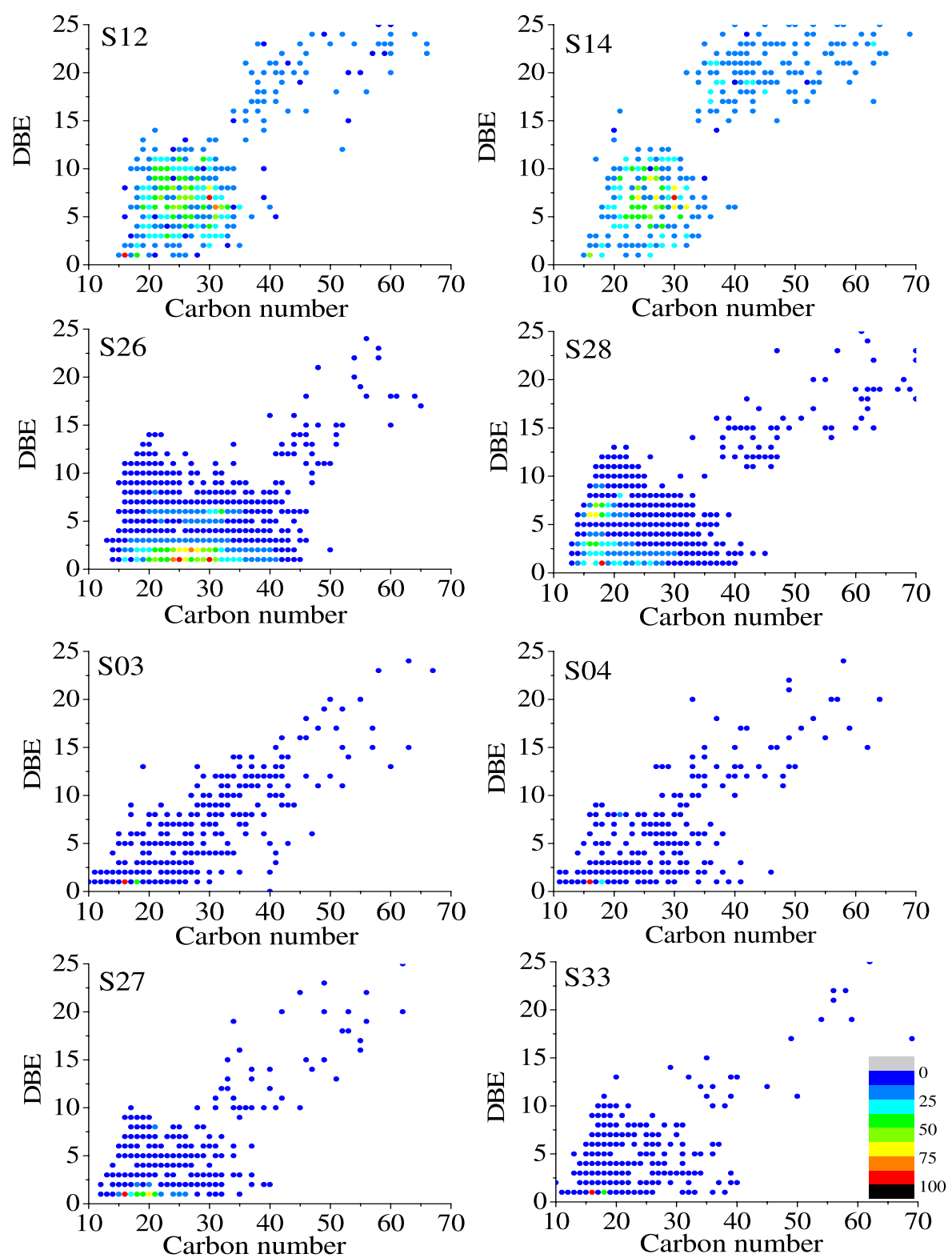

Figure 5. Iso-abundance plots of DBE versus carbon number for $\mathrm{O}_{2}$ class species in acidic fractions. Data derived from negative-ion ESI LTQ Orbitrap XL mass spectra of the following samples: S12 and S14 from dry interdune facies; S26 and S28 from dune foreset facies; S03 and S04 from wet interdune facies; S27 and S33 from dune bottomset facies.

\section{DBE ratios}

The following DBE ratios were calculated based on $\mathrm{O}_{2}$ class distribution: DBE 4/DBE 3, DBE 6/DBE 3, and DBE 8/DBE 3. These ratios were calculated by the sum of the abundances of acidic species with the same number of double bond equivalent (DBEs). The $\mathrm{O}_{2}$ class species with DBE 3, DBE 4, DBE 6, and DBE 8 mainly include bicyclic, tricyclic terpanoic, hopanoic, and naphthalenic acids, respectively. We are proposing these biodegradation ratios based on the fact that biodegradation of O-containing compounds follow a preferential order, in which compounds with less complex structures (lower DBE) are more depleted than those with more complex structures (higher DBE), as it was showed by Angolini et al. ${ }^{30}$ Besides, the DBE 3 was chosen in the ratios denominator due to the higher abundance of bicyclic terpanoic acids in biodegraded oils with PM level lower than 6, which begins to be degraded in higher levels of biodegradation. ${ }^{30,32}$ Figure 6 shows these DBE ratio distributions in the eight bitumen samples.

It can be observed in Figure 6 that the samples from dry interdune facies (S12 and S14), the most biodegraded bitumens, have the highest DBE ratio values. Typically, biodegradation occurs by readily depletion of the less complex compounds in petroleum (hydrocarbon compounds with lower molecular masses), ${ }^{30,40}$ shifting 

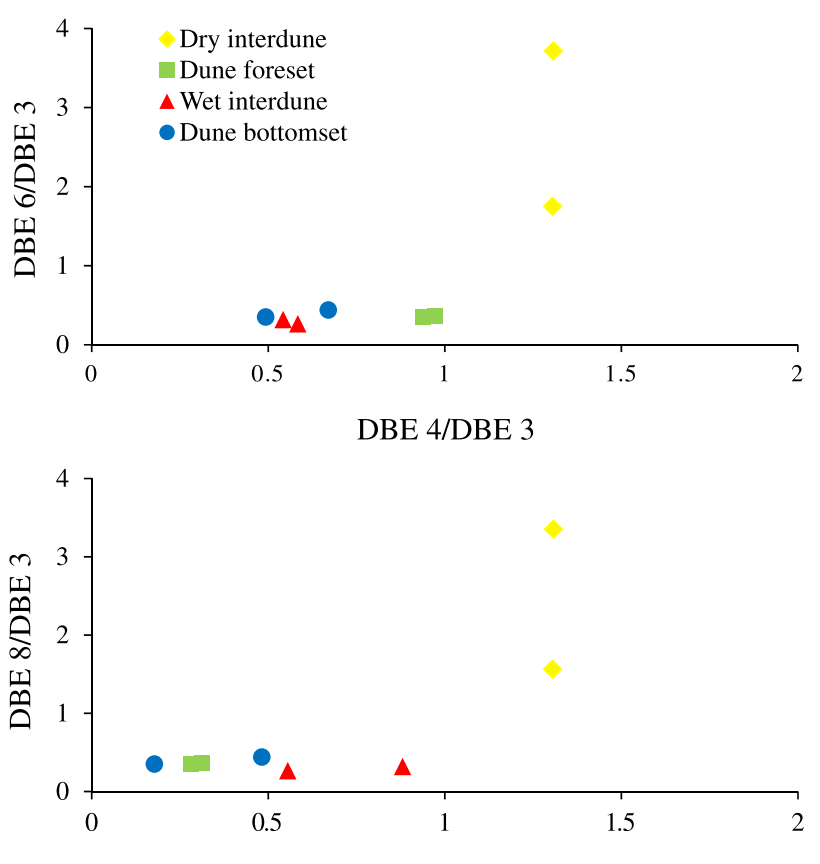

DBE 4/DBE 3

Figure 6. DBE ratios distribution to bitumen samples from the sedimentary facies of Piramboia Formation, Paraná Basin, Brazil.

the maximum of the $\mathrm{O}_{2}$ class to lower levels of DBE. Thus, it could be expected a general decreasing trend in these ratios with increasing biodegradation intensity, since the abundance of compounds with DBE 3 would increase. However, in this work, we found that these ratios exhibit an increasing trend with increasing biodegradation intensity. This result can be explained by the fact that the samples analyzed in this work show evidence of a greater degree of biodegradation (bitumens with a heavy level of biodegradation), ${ }^{38}$ and compounds with less complex structures (DBE 3) were more depleted than those with more complex structures (DBE 4, DBE 6 and DBE 8), as it was already showed by Angolini et al..$^{30}$ This level of biodegradation reached by the samples shows evidence of significant acidic compound biodegradation.

The samples from the other sedimentary facies (S26, S28, S03, S04, S27, and S33) have lowest DBE ratio values. This result suggests a distinct degree of biodegradation between the bitumens from these facies and from dry interdune. Thus, these ratios may be used to evaluate the degree of biodegradation in heavy-oil and tar sand bitumens.

\section{$\mathrm{A} / \mathrm{C}$ ratio}

Kim et $a l . .^{32}$ suggested a biodegradation index to be used for estimating the degree of biodegradation by petroleomics. This index is based on the ratio of acyclic to cyclic naphthenic acids ( $\mathrm{A} / \mathrm{C}$ ratio), in which there is a consistent decrease in acyclic fatty acids and increase in cyclic $\mathrm{O}_{2}$ species with biodegradation. Hughey et al. ${ }^{34}$ tested the robustness of this proposed index and suggested that this biodegradation index is useful in monitoring the biodegradation of a single oil or a suite of genetically related oil, such as the bitumen samples examined in this work. Thus, $\mathrm{A} / \mathrm{C}$ ratios were calculated for the eight bitumen samples, and the results are shown in Figure 7.

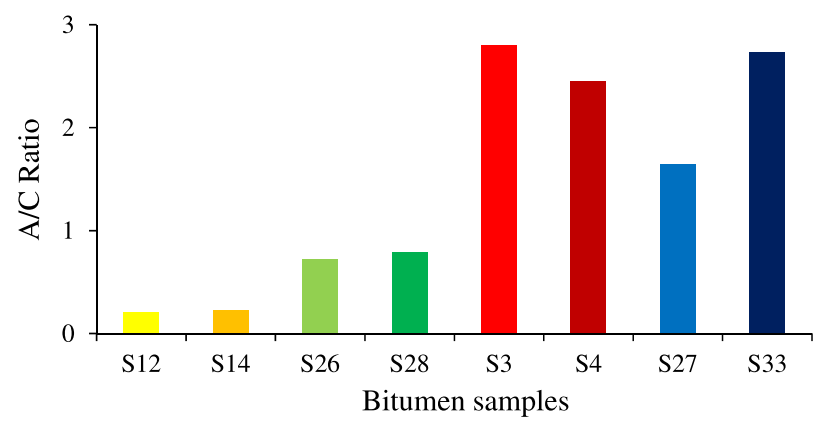

Figure 7. A/C ratios for bitumen samples (S12 and S14 from dry interdune; S26 and S28 from dune foreset; S03 and S04 from wet interdune; S27 and S33 from dune bottomset), calculated from the sum of abundance of acyclic (DBE $=1) \mathrm{O}_{2}$ species divided by the sum of magnitudes of the mono, di-, and tri- cyclic acids $(\mathrm{DBE}=2,3$ and 4$)$.

It can be observed in Figure 7 that the bitumen samples from different sedimentary facies have different A/C ratios. This index is the lowest for bitumens from the dry interdune facies (S12 and S14), the most biodegraded samples, in agreement with the results obtained from the DBE ratios. Therefore, this index is also suitable for assessing the degree of biodegradation in tar sand bitumens, with the lowest values indicating the highest extent of biodegradation.

\section{Conclusions}

The analysis of acidic compounds found in bitumens by negative-ion ESI LTQ Orbitrap XL provides significant analytical results. Because biodegraded oils dominate the world petroleum inventory, and the production of very heavy-oil is likely to increase worldwide as light conventional oil resources are depleted, the importance of polar compound analysis (e.g., petroleomics) for heavy-oils and bitumens increases.

The LTQ Orbitrap XL results based on eight tar sand bitumen samples from the Pirambóia Formation (Paraná Basin, Brazil) show that the acidic species composition (mainly $\mathrm{O}_{2}$ class) is distinct for bitumens from different sedimentary facies, most likely due to the different extents of biodegradation in each facies. The bitumens from the dry interdune facies have the most distinct acidic composition, with the lowest number of acidic species in the $\mathrm{O}_{2}$ and 
$\mathrm{O}_{3}$ classes (mainly in the $\mathrm{O}_{2}$ class), most likely due to depletion of these species with the further biodegradation. However, the relative abundance of the $\mathrm{N}_{1} \mathrm{O}_{0}$ classes is higher in the samples that exhibit evidence of the highest degree of biodegradation, which contain biodegradation products of N-containing compounds. Moreover, the dry interdune facies presents the highest DBE ratios, a new biodegradation parameters proposed in this work, and lowest $\mathrm{A} / \mathrm{C}$ ratios. These results are in agreement with results supporting the highest degree of biodegradation in the bitumens from this facies and indicate that these petroleomics parameters can be used to assess the degree of biodegradation in other bitumen samples, in which the DBE 4/DBE3, DBE 6/DBE 3, and DBE 8/DBE 3 ratios increase and the $\mathrm{A} / \mathrm{C}$ ratio decreases with increasing biodegradation extent.

\section{Acknowledgments}

This work was supported by the Laboratory of Petroleum Engineering and Exploration of the North Fluminense State University (LENEP/UENF) and by the Chemistry Institute, University of Campinas (UNICAMP). Petrobras/Rede de Geoquímica also provided the necessary infrastructure to conduct this research, which was funded by ANP, Capes, and FAPERJ.

\section{References}

1. Koopmans, M. P.; Larter, S. R.; Zhang, C.; Mei, B.; Wu, T.; Chen, Y.; AAPG Bull. 2002, 86, 1833.

2. Wu, Y.; Xia, Y.; Wang, Y.; Lei, T.; Chang, J.; Wang, Y.; J. Pet. Sci. Eng. 2013, 103, 97.

3. Hosseini, S. H.; Shakouri, G. H.; Energy Policy 2016, 91, 64.

4. Flego, C.; Carati, C.; Gaudio, L. D.; Zannoni, C.; Fuel 2013, $111,357$.

5. Hein, F. J.; Leckie, D.; Larter, S.; Suter, J. R. In Heavy-Oil and Oil-Sand Petroleum Systems in Alberta and Beyond; AAPG: Tulsa, USA, 2013.

6. Demaison, G. J.; AAPG Bull. 1977, 61, 1950.

7. Head, I. M.; Jones, D. M.; Larter, S. R.; Nature 2003, 426, 344.

8. Thomaz Filho, A.; Mizusaki, M. P.; Antonioli, L.; Mar. Pet. Geol. 2008, 25, 143.

9. Araújo, C. C.; Yamamoto, J. K.; Rostirolla, S. P.; Madrucci, V.; Tankard, A.; Mar. Pet. Geol. 2005, 22, 671.

10. Caetano-Chang, M. R.; Wu, F. T.; Geociências 2003, 22, 33.

11. Garcia, M. A.; Ribeiro, H. J. P. S.; Souza, E. S.; Triguis, J. A.; Geociências 2011, 30, 357.

12. Palmer, S. E. In Effect of Biodegradation and Water Washing on Crude Oil Composition; Macko, S. A.; Engel, M. H., eds.; Plenum Press: New York, USA, 1993.
13. Jones, D. M.; Head, I. M.; Gray, N. D.; Adams, J. J.; Rowan, A. K.; Aitken, C. M.; Bennett, B.; Huang, H.; Brown, A.; Bowler, B. F. J.; Oldenburg, T.; Erdmann, M.; Larter, S. R.; Science 2008, 451, 176.

14. Aitken, C. M.; Jones, D. M.; Larter, S. R.; Nature 2004, 8, 291.

15. Da Cruz, G. F.; Santos Neto, E. V.; Marsaioli, A. J.; Org. Geochem. 2008, 39, 1204.

16. Vasconcellos, S. P.; Crespim, E.; Cruz, G. F.; Senatore, D. B.; Simioni, K. C. M.; Santos Neto, E. V.; Marsaioli, A. J.; Oliveira, V. M.; Org. Geochem. 2009, 40, 574.

17. Da Cruz, G. F.; Vasconcellos, S. P.; Angolini, C. F. F.; Dellagnezze, B. M.; Garcia, I. N. S.; De Oliveira, V. M.; Santos Neto, E. V.; Marsaioli, A. J.; AMB Express 2011, 1, article 47.

18. Jones, D. M.; Head, I. M.; Gray, N. D.; Adams, J. J.; Rowa, A. K.; Aitken, C. M.; Bennett, B.; Huang, H.; Brown, A.; Bowler, B. F. J.; Nature 2007, 451, 176.

19. Connan, J.; In Advances in Petroleum Geochemistry, vol. 1; Brooks, J.; Welte, D. H., eds.; Academic: London, UK, 1984.

20. Meredith, W.; Kelland, S. J.; Jones, D. M.; Org. Geochem. 2000, 31, 1059.

21. Hsu, C. S.; Drinkwater, D.; In Current Practice of Gas Chromatography-Mass Spectrometry; Niessen, W. M. A., ed.; Marcel Dekker: New York, USA, 2001.

22. Liao, Y.; Shi, Q.; Hsu, C. S.; Pan, Y.; Zhang, Y.; Org. Geochem. 2012, 47, 51 .

23. Hughey, C. A.; Hendrickson, C. L.; Rodgers, R. P.; Marshall, A. G.; Anal. Chem. 2001, 73, 4676.

24. Marshall, A. G.; Hendrickson, C. L.; Annu. Rev. Anal. Chem. 2008, 1,578 .

25. Fenn, J. B.; Mann, M.; Meng, C. K.; Wong, S. F.; Whitehouse, C. M.; Science 1989, 246, 64.

26. Robb, D. B.; Covey, T. R.; Bruins, A. P.; Anal. Chem. 2000, 72 , 3653.

27. Hsu, C. S.; Hendrickson, C. L.; Rodgers, R. P.; McKennam, A. M.; Marshall, A. G.; J. Mass Spectrom. 2011, 46, 337.

28. Kaiser, N. K.; McKenna, A. M.; Savory, J. J.; Hendrickson, C. L.; Marshall, A. G.; Anal. Chem. 2013, 85, 265.

29. Pomerantz, A. E.; Mullins, O. C.; Paul, G.; Ruzicka, J.; Sanders, M.; Energy Fuel 2011, 25, 3077.

30. Angolini, C. F. F.; Capilla, R.; Marsaioli, A. J.; Energy Fuel 2015, 29, 4886.

31. Marshall, A. G.; Rodgers, R. P.; PNAS 2008, 105, 18090.

32. Kim, S.; Stanford, L. A.; Rodgers, R. P.; Marshall, A. G.; Walters, C. C.; Qian, K.; Wenger, L. M.; Mankiewicz, P.; Org. Geochem. 2005, 36, 1117.

33. Vaz, B. G.; Silva, R. C.; Klitzke, C. F.; Simas, R. C.; Nascimento, H. D. L.; Pereira, R. C. L.; Garcia, D. F.; Eberlin, M. N.; Azevedo, D. A.; Energy Fuel 2013, 27, 1277.

34. Hughey, C. A.; Samantha, A. G.; John, E. Z.; Fuel 2007, 86, 758. 
35. Smith, D. F.; Schaub, T. M.; Kim, S.; Rodgers, R. P.; Rahimi, P.; Teclemariam, A.; Marshall, A. G.; Energy Fuel 2008, 22, 2372.

36. Mapolelo, M. M.; Rodgers, R. P.; Blakney, G. T.; Yen, A. T.; Asomaning, S.; Marshall, A. G.; Int. J. Mass Spectrom. 2011, 300, 149 .

37. Martins, L. L.; Franklin, G. C.; Souza, E. S.; da Cruz, G. F.; Quim. Nova 2014, 37, 1263.

38. Martins, L. L.; da Cruz, G. F.; Souza, E. S.; Ribeiro, H. J. P. S.; Geochim. Bras. 2015, 29, 154.

39. Koike, L.; Rebouças, L. M. C.; Reis, F. A. M.; Marsaioli, A. J.; Richnow, H. H.; Michaelis, W.; Org. Geochem. 1992, 18, 851.

40. Peters, K. E.; Moldowan, J. M.; The Biomarker Guide, $1^{\text {st }}$ ed.; Prentice Hall: New York, USA, 1993.
41. Harwood, C. S.; Burchhardt, G.; Herrman, H.; Fuchs, G.; FEMS Microbiol. Rev. 1998, 22, 439.

42. Wentzel, A.; Ellingsen, T. E.; Kotlar, H. K.; Zotchev, S. B.; Holst, M. T.; Appl. Microbiol. Biotechnol. 2007, 76, 1209.

43. Watson, J. S.; Jones, D. M.; Swannell, R. P. J.; Van Duin, A. C. T.; Org. Geochem. 2002, 33, 1153.

44. Shi, Q.; Zhao, S.; Xu, Z.; Chung, K. H.; Zhang, Y.; Xu, C.; Energy Fuel 2010, 24, 4005.

Submitted: March 28, 2016

Published online: August 16, 2016

FAPESP has sponsored the publication of this article. 